\title{
correspondence
}

\section{Crowther-Hunt's proposals}

Sir,-Your leading article (May 29) outlines proposals which Lord Crowther-Hunt anticipates the academic community will eventually endorse. He wants the opinion of university teachers in order to support his own case, but any alteration in the role of universities in Britain will of necessity require discussion among teachers, employers and students.

Lord Crowther-Hunt should ask his colleagues in the government, 'did they suffer or did they benefit from a university education?'

It is facile to quote a figure of 400,000 in full-time tertiary education and the commitment to increase this number to 640,000 by 1981 . Has anyone gauged opinions among students, because it would seem that from an economic standpoint there is a distinct disadvantage in pursuing tertiary education. As one graduating student said to me, "I feel cheated because at school I was told that job opportuni. ties would increase enormously if I had a degree and now four years later the choice of jobs is very limited".

In my own department, where some $65-70 \%$ of young graduates have obtained a higher degree, we see trained personnel leaving the country because of lack of opportunity. Although this provides some academic benefit to our department, it is almost impossible for these people to return to the UK. I know of two instances where our graduates could only afford to return if they were given professorships, because of the low salary scales in Britain.

In 1967 the Committee of ViceChancellors and Principals carried out a survey of the hours worked by university staff. An example of the hours/ week was 54 for a vacational period, 63 for term-time and 80 for an examination period. University teachers do not receive remuneration for the vast amount of work which they take home. I wonder how many trade unions would tolerate a situation in which conditions of service are so loosely defined. Recently, Dr Alex Comfort commented on the situation in one research institute where "geriatric cases some of them, drawing fat salaries for years and doing absolutely nothing" created an impression of idleness among all the staff. Such situations are not unknown in universities and could be controlled with a scheme of voluntary retirement before the official retiring age.

It might be considered relevant to design courses to meet the needs of the country but it would surely follow that relevant employment with a career structure should be available at the end of the course.

In 1968, however, a learned society formed a temporary committee for liaison between employers and teachers. The conflicting demands of employers were such that it was considered to be almost impossible to design a completely acceptable course for all employers. One must realise, therefore, that the demands of the employer should not dominate the discussion.

The increase in student-staff ratios from $8.4: 1$ to $10-11: 1$ is irrelevant when considering increased productivity and the number of staff to be retained in universities. The studentstaff ratio or FTE (formal teaching equivalent) does not include the requirement for repetitive teaching to small aliquots of one large class, that is, the staff time involved to complete one course. I would suggest that increased expansion and productivity, if it is desirable, is a function of staffstudent ratios, staff-time per student, space to accommodate larger classes, job opportunities, salaries, rationalisation of university courses, the needs of the country and continued investment in universities.

The last proposal to examine the balance between teaching and research in universities is very important. In view of the anticipated increase in time spent on teaching it seems that Lord Crowther-Hunt is proposing a reduction in research programmes. The subsequent effects of such a move would be disastrous. The move would not immediately affect the quality of teaching but would eventually affect the quality of universities. This would severely affect student populations and bright students would flee. There is a school of opinion which believes that the present government equates private education in the secondary field with universities in the tertiary field of education. Before Lord Crowther-Hunt and his colleagues in the Department of Education and Science run the bulldozer over the universities and produce comprehensive tertiary education they should consider the consequences. D. E. S. Stewart-Tull

Microbiology Department,

University of Glasgow, $U K$

\section{English and editorial boards}

Sir,-Dr M. Charles (May 8) wonders what members of the editorial board of certain journals do, apart from collecting an annual fee and refereeing a paper or two. Speaking as a literary hack whose job it is to edit such papers so as to give them a veneer of literary and scientific competence, I question whether these august editorial names ever referee any of the papers submitted because (a) they would not be able to understand some of the appallingly ill-written stuff, (b) if they could understand it they would realise that much of it is not worth publishing.

Papers submitted in English by authcrs with another mother tongue are certainly ofiten unintelligible, but it must be confessed that some native efforts from certain of our English universities and technical colleges run them pretty close. This is due to the recent proliferation of such institutes, with the result that anyone who is not actually moronic can now qualify for higher education. The effect is that people who in saner times would be happily and usefully employed behind the counter of the local grocer's now feel impelled to give the world the fruits of their intellectual labours.

J. C. ANDrEwES

Cambridge, UK

\section{Not worried}

SIR,-I really rubbed my eyes at your contributor John Hall's statement that in Cambridge "The number taking chemistry is so small that professors are starting to worry about the security of their salaries ..." (Nature, May 22). The facts are precisely the reverse. The number of third year students opting for chemistry at Cambridge has risen steadily over the past three years and there is already a firm indication of 70 for next year's numbers (the final figure is usually above this initial assessment). The postgraduate situation here shows a similar robust health, particularly in organic chemistry, where it is clear from the shoal of applications that every available place will be filled. I can therefore reassure John Hall that he need not rattle a collecting box for Cambridge chemistry professors just yet.

R. A. RaphaEL

University Chemistry Laboratory,

Cambridge, UK 